\title{
An Experimental Investigation of Modern Savonius Turbine Equipped with Arm Geared Based Structure for Electric Power Generation
}

\author{
Prof. Ashish S. Dhunde ${ }^{1}$, Prof. Samrat M. Kavishwar ${ }^{2}$, Chetan S. Lohande ${ }^{3}$, Chakradhar L. Bhoyar ${ }^{4}$, \\ Deepak B. Kumbhar ${ }^{5}$, Golu M. Choure ${ }^{6}$, Neha P. Ramteke ${ }^{7}$ \\ 1,2Assistant Professor, 3,4,5,6,7BE Scholar \\ Department of Mechanical Engineering, NIT College of Engineering and Technology, Nagpur, India
}

\begin{abstract}
As per latest situation the electricity is the biggest issue therefore whereas taken all the items into thought here effectively created a complicated system i.e. an Experimental investigation of contemporary savonius rotary engine equipped with arm intermeshed based mostly structure for electrical power generation. this is the advanced recurvate formed rotary engine. This rotary engine is essentially a hybrid rotary engine which means this rotary engine will able to work on water, air, etc. This rotary engine is basically a advanced rotary engine will able to work on minimum revolution.
\end{abstract}

According to structure of savonius rotary engine, as its curved dome it covers most air flow, water force etc. therefore utilization of panel is most. this technique is hybrid electricity generation which means it works on air, water grain etc. this system primarily is helpful for home application, faculties and schools, hospitals, shipping malls, auditoriums.

Now a day's power requirement is that the biggest demand within the growing world since last decade. this technique is works as an entire hybrid turbine and connected electricity generation if modification are done consistent with demand and connected output. this system is multi station therefore will able to generate electricity through multiple generators, with single rotary engine with the utilization of gear wheel arrangement and connected gear arrangement.

This system is shock resistant, straightforward to store, rev based mostly output, straightforward to place and transfer and attainable to dissemble and assemble simply in order that with the matter.

Keywords : Savonius Turbine, Air, Water, Grain.

\section{INTRODUCTION}

As per the technical evolution and technical trends taken into thought thus we created a "Modern savonius rotary engine equipped with arm geared based structure for electrical power generation". this technique uses an stylish savonius rotary engine that is ready to rotate over multiple natural resources water force, energy and connected things having efficiency greater than mechanics rotary engine. The advancement of this rotary engine is that, this rotary engine not exclusively rotate over multiple natural resources and artificial resources but in addition having capability of resources settlement into it to keep with multiple savonius blade structure.

The advantages of this project as compared to different types of system is that, on one single Savonius structure unit we can ready to rotate multiple powerhouse and various powerhouse uses single rotary engine that is able to rotate solely single generator. Therefore power output is further 
economical than that normal. This project able to implement at industries, factories, agricultural areas, home, airport, hill station and artificial creations.

This is not straightforward an easy structure like straightforward turbine typically this can be often modern ideas specially taken vision over various natural resources and artificial resources. This structure having natural resources settlement and reutilization capability, which means this structure not exclusively uses multiple resources i.e. wind power, water force and completely different however in addition settle them to reutilization thus this rotary engine rotate with further toque and ready to turn out additional output thus ready to $\}$ in a position to charge battery at intervals minimum time.

Savonius turbines unit a form of vertical-axis turbine (VAWT), used for converting the force of the wind into torsion on a rod. The rotary engine consists of sort of aerofoils, generally however not constantly vertically mounted on a rod or framework, either ground stationed or certain in mobile systems.

The Savonius rotary engine is one of the simplest turbines. Aerodynamically, it is a drag-type device, consisting of four curve shape blade machine would seem as if turbine "U" type in cross section. because of the curv shape it experience less drag once moving against the wind than once moving with the wind. The differential drag causes the Savonius turbine to spin. as a results of they're drag-type devices, Savonius turbines extract ample less of the wind's power than various similarly-sized lift-type turbines. ample of the swept house of a Savonius rotor is also about to rock bottom, if it is a little mount whereas not an extended post, making the final energy extraction less effective because of the lower wind speeds found at lower heights.
Savonius turbines unit used whenever price or reliability is far further necessary than potency.

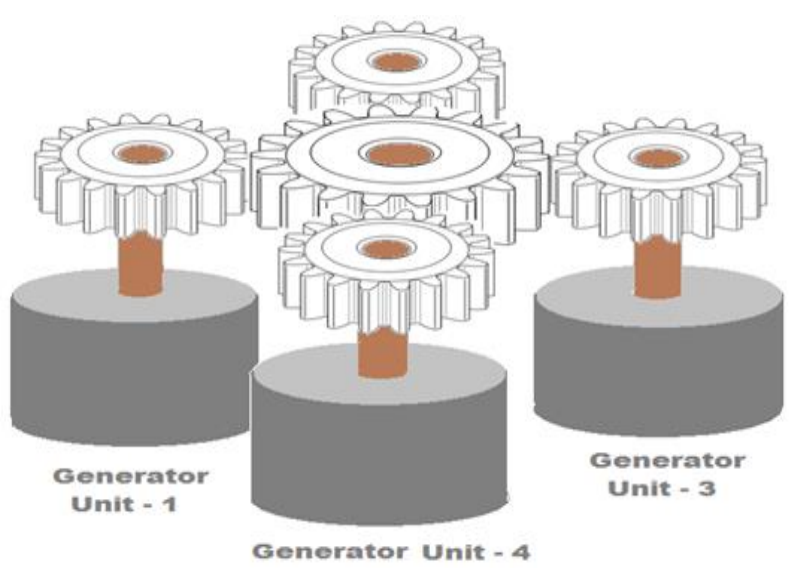

Fig.1 Main Savonius Assembly

\section{CONCEPT}

In this project with the assistance of natural available resources i.e. non-conventional energy supply water, air, Water mud, stones and grains and mistreatment gravitation force here created a mechanism i.e. advanced rotary engine rotates. With the movement of this rotary engine consequently main arm will rotate. there's coupling between rotary engine and main arm in order that we are able to replace this rotary engine efficiently while not touching the opposite system.

Main arm having two totally different mechanisms coupled with this and in keeping with force transfer, inside single rotation of rotary engine the arm and mechanism rotates no. of times. According to force transfer, inside single rotation of rotary engine the main arm and mechanism rotates multiples times so that with the one rotation of main arm, sub arm also rotates multiple times and similarly with the one rotation of sub arm generator rotates multiple times thus effectively force transfer from rotary engine to generator. 
That means within restricted handiness of Renewable or non-conventional energy supply and with minimum rotation of rotary engine the generator rotates no of times that is the advantage of this method

\section{METHODOLOGY}

\section{Working Principle}

This experiment uses main arm having massive diameter with some thickness. This main arm is conected with the savonius unit, so tht with the rotation of savonius unit, the main arm rotates. The main arm is smaller that of savonius unit. The main arm having major gear/wheel whose revolution are going to be bigger than that of savonius unit meaning for single rotation of savonius unit the main arm rotates multiple times. This advantage that is beneficial to extend the revolution of main arm consequently sub arm, via savonius unit.

\section{Components \& Constructional Details:}

As per the technical evolution and technical trends taken into thought thus we created a "Modern savonius rotary engine equipped with arm geared based structure for electrical power generation". this technique uses an stylish savonius rotary engine that is ready to rotate over multiple natural resources water force, energy and connected things having efficiency greater than mechanics rotary engine. The advancement of this rotary engine is that, this rotary engine not exclusively rotate over multiple natural resources and artificial resources but in addition having capability of resources settlement into it to keep with multiple savonius blade structure.

The advantages of this project as compared to different types of system is that, on one single Savonius structure unit we can ready to rotate multiple powerhouse and various powerhouse uses single rotary engine that is able to rotate solely single generator. Therefore power output is further economical than that normal. This project able to implement at industries, factories, agricultural areas, home, airport, hill station and artificial creations.

This Project Consists of 4 different Units:

1. Savonius Unit

2. Main Arm.

3. Sub Arm

4. Multi-station Generator Unit

\section{Savonius Unit:}

Savonius turbines unit a form of vertical-axis turbine (VAWT), used for converting the force of the wind into torsion on a rod. The rotary engine consists of sort of aerofoils, generally however not constantly vertically mounted on a rod or framework, either ground stationed or certain in mobile systems.

The Savonius rotary engine is one of the simplest turbines. Aerodynamically, it is a drag-type device, consisting of four curve shape blade machine would seem as if turbine "U" type in cross section. because of the curv shape it experience less drag once moving against the wind than once moving with the wind. The differential drag causes the Savonius rotary engine to spin. as a results of they're drag-type devices, Savonius turbines extract ample less of the wind's power than various similarly-sized lift-type turbines. ample of the swept house of a Savonius rotor is also about to rock bottom, if it is a little mount whereas not an extended post, making the final energy extraction less effective because of the lower wind speeds found at lower heights.

\section{Main Arm:}

We use two gears having with some thickness and larger in diameter called as main arm. This main arm is connected with the turbine shaft so that according to the rotation of savonius turbine, the main arm gear 
also rotates. The main arm gear is smaller in diamension that of savonius turbine unit. The main arm having major gear wheel whose RPM will be greater than that of turbine so that for single rotation of turbine the main arm rotates no of time.

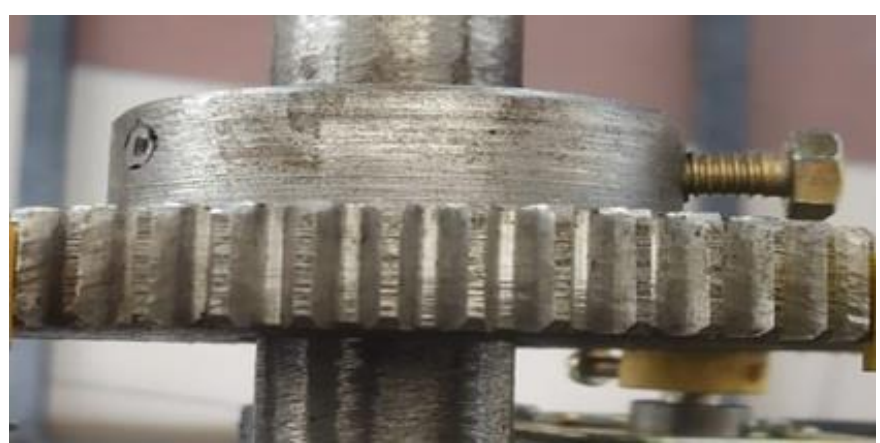

Fig 2:- Main Arm

\section{Sub Arm:}

In this project, here used four sub arms, these eight arm square measure nothing however the eight gears that is link with main arm gear. Ultimately the rotation savonius unit, main arm rotates and consequently sub four arm rotates. The gear assembly of four arm square measure created in step with increase most revolutions per minute stepwise from savonius unit to main arm and main arm to sub arm. This sub arm present during a multi station structure type, therefore according we are able to connect multiple generator unit .

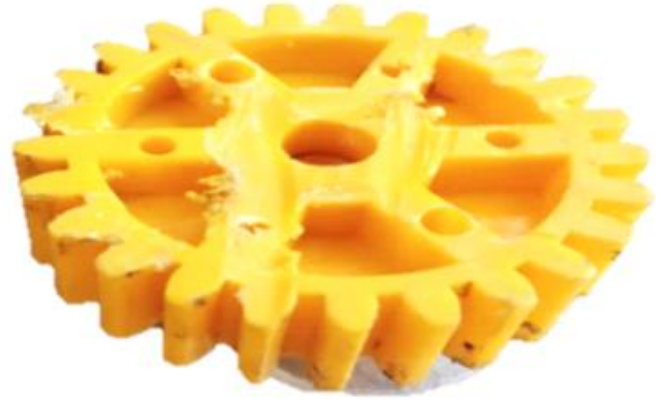

Fig 3 :- Sub Arm

\section{Generator Unit:}

This project used multi-station structure meaning over one savonius unit and single main arm, here used multiple sub arm and consequently multiple generator. This assembly works from savonius unit to generator with increase in rate kind meaning with minimum ntural or artificial resources i.e, wind power, waterforce and etc. The savonius structure rotates with minimum quantity of energy. This rotation helps to rotate main arm with bigger rate than that of savonius rotary engine. the most arm helps to rotate sub multiple arms .the rate of sub arm is bigger than main arm and consequently the generator i.e, four multiple generator rotates with bigger rate.

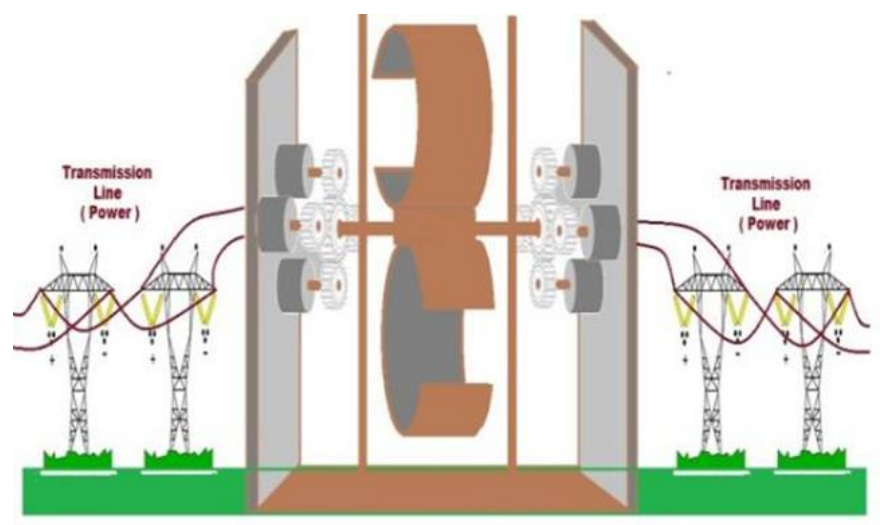

Fig 4 :- Generator Unit

\section{Savonius Turbine blade}

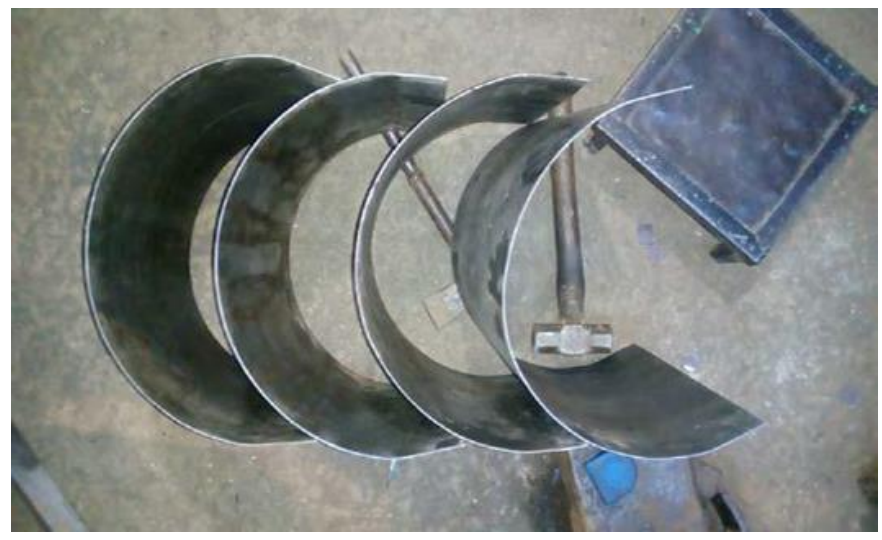

Fig 5:- Savonius Turbine Blade

Here we'll discuss the blade material, size and kind. during this experiment we tend to determined to use Al for Material but u can use steel, Puck Board, or maybe an easy 5 gal pale flip over a combine of or $45 \mathrm{gal}$ drum flip over a combine of, varied decisions 
we get got for the blades. the scale for blade is twelve.5" width, 6.25" depth, 0.125"thick, 20" circumference and 18" high. Savonius turbines is sort of vertical-axis turbine (VAWT), in that the force of the wind transfer on a rod. The rotary engine consists of sort of aerofoils, typically but not constantly vertically mounted on a rod or framework, either ground stationed or certain in mobile systems.

The Savonius rotary engine is one in every of the simplest turbines. Aerodynamically, it's a drag-type device, consisting of two or three scoops. wanting down on the rotor from on prime of, a a pair of scoop machine would seem as if seen lilke "S" kind in cross section. The results of the curve shape generate less drag once moving in opposite to the wind and another moving with the wind. The differential drag causes the Savonius rotary engine to spin. as a results of they are drag-type devices, Savonius turbines extract a lot of less of the wind's power than completely different similarly-sized lift-type turbines. heaps of of the swept house of a Savonius rotor might be on the point of rock bottom, if it's atiny low mount whereas not academic degree extended post, produce overall energy generation is less effective as a result of the lower wind speeds found at small heights.

\section{Gear Mechanism Arrangement:}

This project used multi-station structure which suggests over one savonius unit and single main arm, here used multiple sub arm and consequently multiple generator. As per the mechanism shown in fig(a). The four sub arm are constantly meshed with main arm. therefore the four sub arm square measure rotate in single rotation of main arm and with the rotation of sub arm generator square measure rotate that is the sub arm and generate power. this type of drugs mechanism is to boot organized in numerous side of the rotary engine shaft as shown in fig where same assembly is to be created.

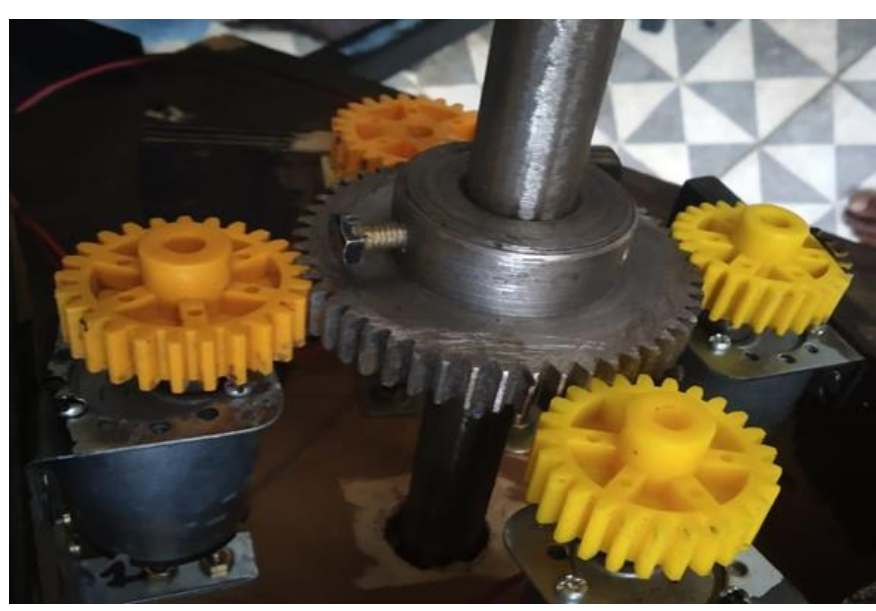

Fig 6 :- Gear mechanism arrangement

\section{Block diagram}

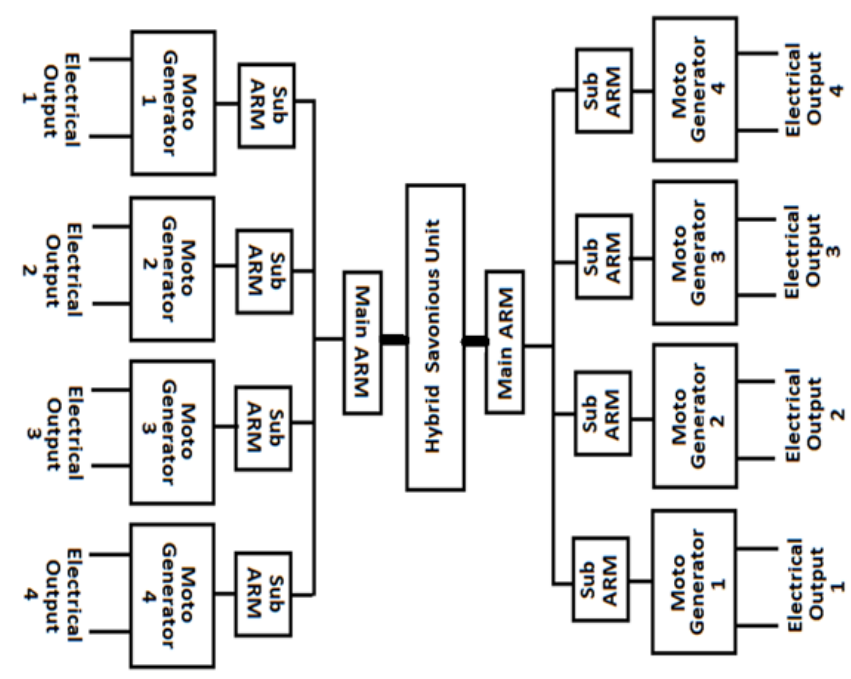

Fig 7 :- Block Diagram of Savonius Unit

\section{FABRICATED MODEL}




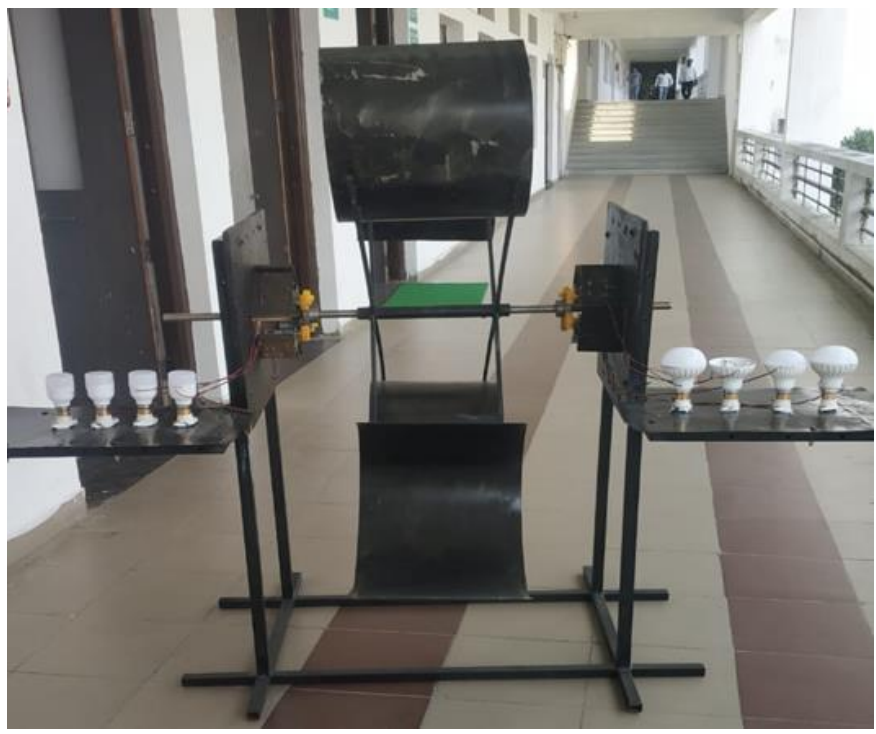

Fig.8 :- Modern Savonius With Arm Gear Based Structure model

\section{TABLE I}

Experiment Model tested Output for Single Generator

\begin{tabular}{|c|c|c|c|c|c|}
\hline $\begin{array}{c}\text { Savnious } \\
\text { Rotor } \\
\text { speed (N) } \\
\text { rpm) }\end{array}$ & $\begin{array}{c}\text { Driver } \\
\text { gear } \\
\text { speed } \\
\left(\mathrm{N}_{1}\right) \\
\text { rpm }\end{array}$ & $\begin{array}{c}\text { Driven } \\
\text { gear } \\
\text { speed } \\
\left(\mathrm{N}_{2}\right) \\
\mathrm{rpm}\end{array}$ & $\begin{array}{c}\text { Voltage } \\
(\mathrm{V})\end{array}$ & $\begin{array}{c}\text { Current } \\
(\mathrm{mA})\end{array}$ & $\begin{array}{c}\text { Power } \\
(\mathrm{W})\end{array}$ \\
\hline 20 & 180 & 720 & 8.12 & 0.200 & 1.6 \\
\hline 30 & 270 & 1080 & 10.02 & 0.371 & 3.71 \\
\hline 40 & 360 & 1440 & 11.22 & 0.565 & 6.33 \\
\hline 50 & 450 & 1800 & 18.24 & 0.769 & 14.02 \\
\hline 60 & 540 & 2160 & 20.10 & 0.980 & 19.69 \\
\hline
\end{tabular}

\section{TABLE II}

Therefore Output for four DC Generator

\begin{tabular}{|c|c|c|c|c|c|}
\hline $\begin{array}{c}\text { Savnious } \\
\text { Rotor } \\
\text { speed (N) } \\
\text { rpm) }\end{array}$ & $\begin{array}{c}\text { Driver } \\
\text { gear } \\
\text { speed } \\
\left(\mathrm{N}_{1}\right)\end{array}$ & $\begin{array}{c}\text { Driven } \\
\text { gear } \\
\text { speed } \\
\left(\mathrm{N}_{2}\right)\end{array}$ & $\begin{array}{c}\text { Voltage } \\
(\mathrm{V})\end{array}$ & $\begin{array}{c}\text { Current } \\
(\mathrm{mA})\end{array}$ & $\begin{array}{c}\text { Power } \\
(\mathrm{W})\end{array}$ \\
\hline 20 & 180 & 720 & 32.48 & 0.200 & 6.49 \\
\hline 30 & 270 & 1080 & 40.08 & 0.371 & 14.86 \\
\hline
\end{tabular}

\begin{tabular}{|c|c|c|c|c|c|}
40 & 360 & 1440 & 44.88 & 0.565 & 25.35 \\
\hline 50 & 450 & 1800 & 72.96 & 0.769 & 56.10 \\
\hline 60 & 540 & 2160 & 80.4 & 0.980 & 78.79 \\
\hline
\end{tabular}

Comparison between this experiment output with existing system by graph :-

\section{1) Voltage vs Voltage}

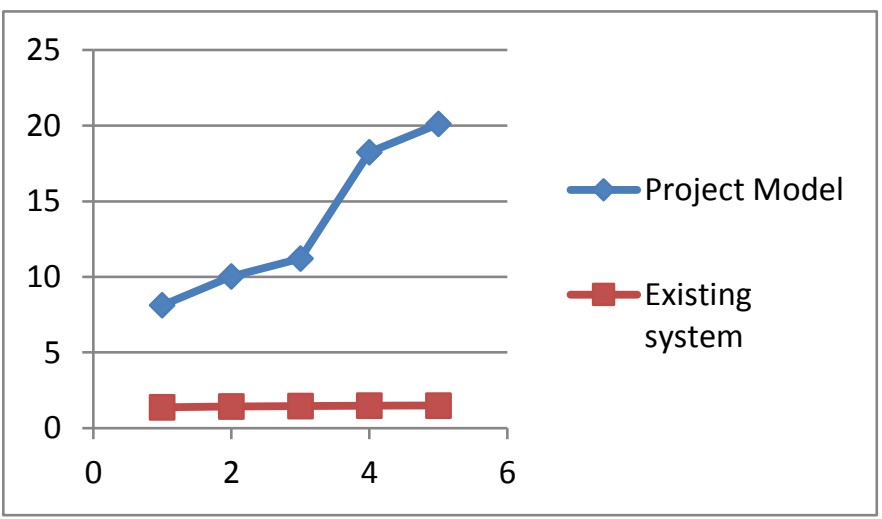

Fig 9 :- Column Chart of Gap Graph of RPM v/s Voltage

As per the above graph, it is easy to conclude that the experiment of model outputs for given voltage is more better and much higher as compare with existing present system result. As the speed of savonius turbine rotor increases then its result that the voltage production increases. That's why the experiment model voltage graph is goes to higher side.

\section{Current vs Current}

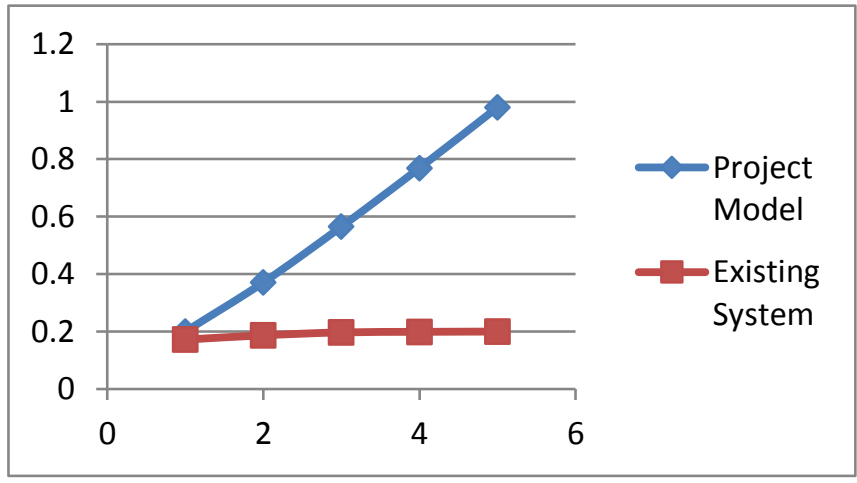

Fig 10 :- Column Chart of Gap Graph of Current v/s Current 
As per the above graph, it is easy to conclude that the experiment of model outputs for given is more better and much higher as compare with existing present system result. As the speed of savonius turbine rotor increases then its result that the current production increases. That's why the experiment model current graph is goes to higher side.

\section{Power vs Power}

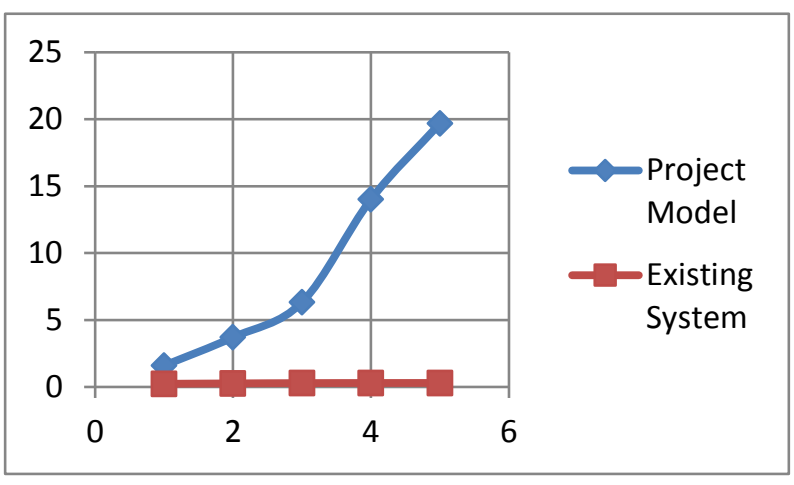

Fig 11 : Column Chart of Gap Graph of Power vs Power

As per the above graph, it is easy to conclude that the experiment of model outputs for given power is better and much higher as compare existing present system result. As the speed of savonius turbine rotor increases then then its result that the voltage production increases. This result directly relate to current. So that alternately current is also goes on higher. So by this V and I it is easy to calculate power for different rpm of turbine and hence That's why the experiment model current graph is goes to higher side.

\section{Advantages:}

- Hybrid structure so able to rotate at any type if natural and artificial resources..

- Ability to handle multiple power station and respective load.

- Highly Efficient and optimized.

- Effective utilization with available resources.

- Artificial Resources also possible..

\section{Applications:}

- Hospitals \& Public Health Centers.

- Diagnosis Centers.

- Home for self-checking.

- School, Colleges for self-checking..

- Rest house for self-checking.

- Pathology labs.

\section{v. CONCLUSION}

The rotation of eight generator units relies on main arm followed by savonius unit with double-geared coupling. This structure i.e. single savonius turbine with no of power generating stations over single arm not only provides efficiency to the system but also increases utility with multiple power generation stations. As per the result shown in tables having power output nearly six times than standard system. And system having four generators, mix able to become more effective wind generation plant which is able to handle massive load.

We can use this method in industrial region wherever large power is needed also we can use this method in agricultural space wherever there's no accessibility of power in order that we will able to cowl larger region for power distribution. Within the advancement of this experimental project if we are trying to increase the power generator capability and enormous savonius turbine unit with increase range of generators units therefore we can be able to generate large amount of power arrange with optimized value and appropriate power.

\section{REFERENCES}

[1]. Blackwell BB, Sheldahl R, Feltz LV. Wind Tunnel Performance Data for Two and Three Bucket SavoniusRotor. Journal of Energy ;

[2]. Le Gourieres D. Wind Power Plants Theory and Design; Pergamon Press Ltd, 1982. 
[3]. Murat Islam on year 2010 Design and development of vertical axis Micro wind Turbine.

[4]. Renewable energy sources by G.D. RAI,chapter:- Wind energy.

[5]. Abramovich, H. 1987. Vertical Axis Wind Turbines: A Survey And Bibliography

[6]. TurbineBlades.URL:http://www.daviddarling.in fo/encyclopedia/B/AE_blades.html (cited January 1, 2008)

\section{Cite this article as :}

Prof. Ashish S. Dhunde, Prof. Samrat M. Kavishwar, Chetan S. Lohande, Chakradhar L. Bhoyar, Deepak B. Kumbhar, Golu M. Choure, Neha P. Ramteke, "An Experimental Investigation of Modern Savonius Turbine Equipped with Arm Geared Based Structure for Electric Power Generation", International Journal of Scientific Research in Science and Technology (IJSRST), Online ISSN : 2395-602X, Print ISSN : 23956011, Volume 7 Issue 2, pp. 539-546, March-April 2020. Available at doi : https://doi.org/10.32628/IJSRST207292 Journal URL : http://ijsrst.com/IJSRST207292 